NASA/TM-2013-217817

\title{
Effects of Microstructural Variability on Thermo-Mechanical Properties of a Woven Ceramic Matrix Composite
}

Marlana B. Goldsmith, Bhavani V. Sankar, and Raphael T. Haftka

University of Florida, Gainesville, Florida

Robert K. Goldberg

Glenn Research Center, Cleveland, Ohio 


\section{NASA STI Program . . . in Profile}

Since its founding, NASA has been dedicated to the advancement of aeronautics and space science. The NASA Scientific and Technical Information (STI) program plays a key part in helping NASA maintain this important role.

The NASA STI Program operates under the auspices of the Agency Chief Information Officer. It collects, organizes, provides for archiving, and disseminates NASA's STI. The NASA STI program provides access to the NASA Aeronautics and Space Database and its public interface, the NASA Technical Reports Server, thus providing one of the largest collections of aeronautical and space science STI in the world. Results are published in both non-NASA channels and by NASA in the NASA STI Report Series, which includes the following report types:

- TECHNICAL PUBLICATION. Reports of completed research or a major significant phase of research that present the results of NASA programs and include extensive data or theoretical analysis. Includes compilations of significant scientific and technical data and information deemed to be of continuing reference value. NASA counterpart of peer-reviewed formal professional papers but has less stringent limitations on manuscript length and extent of graphic presentations.

- TECHNICAL MEMORANDUM. Scientific and technical findings that are preliminary or of specialized interest, e.g., quick release reports, working papers, and bibliographies that contain minimal annotation. Does not contain extensive analysis.

- CONTRACTOR REPORT. Scientific and technical findings by NASA-sponsored contractors and grantees.
- CONFERENCE PUBLICATION. Collected papers from scientific and technical conferences, symposia, seminars, or other meetings sponsored or cosponsored by NASA.

- SPECIAL PUBLICATION. Scientific, technical, or historical information from NASA programs, projects, and missions, often concerned with subjects having substantial public interest.

- TECHNICAL TRANSLATION. Englishlanguage translations of foreign scientific and technical material pertinent to NASA's mission.

Specialized services also include creating custom thesauri, building customized databases, organizing and publishing research results.

For more information about the NASA STI program, see the following:

- Access the NASA STI program home page at http://www.sti.nasa.gov

- E-mail your question to help@sti.nasa.gov

- Fax your question to the NASA STI Information Desk at 443-757-5803

- Phone the NASA STI Information Desk at 443-757-5802

- Write to: STI Information Desk NASA Center for AeroSpace Information 7115 Standard Drive Hanover, MD 21076-1320 
NASA/TM-2013-217817

\section{Effects of Microstructural Variability on Thermo-Mechanical Properties of a Woven Ceramic Matrix Composite}

Marlana B. Goldsmith, Bhavani V. Sankar, and Raphael T. Haftka

University of Florida, Gainesville, Florida

Robert K. Goldberg

Glenn Research Center, Cleveland, Ohio

National Aeronautics and

Space Administration

Glenn Research Center

Cleveland, Ohio 44135 


\section{Acknowledgments}

The funding for this work was provided by the NASA Graduate Student Research Program, grant number NNX10AM49H. The authors are thankful to Kim Bey of NASA Langley Research Center (LaRC) for many helpful discussions. Also, thanks to Peter Bonacuse of NASA Glenn Research Center (GRC) for the model generation code as well as the parameter sample distributions, and to Subodh Mital of The University of Toledo and GRC for helpful discussions regarding finite element modeling and OOF2.

Trade names and trademarks are used in this report for identification only. Their usage does not constitute an official endorsement, either expressed or implied, by the National Aeronautics and Space Administration.

This work was sponsored by the Fundamental Aeronautics Program at the NASA Glenn Research Center.

Level of Review: This material has been technically reviewed by technical management.

Available from

NASA Center for Aerospace Information 7115 Standard Drive

Hanover, MD 21076-1320
National Technical Information Service 5301 Shawnee Road Alexandria, VA 22312 


\title{
Effects of Microstructural Variability on Thermo-Mechanical Properties of a Woven Ceramic Matrix Composite
}

\author{
Marlana B. Goldsmith, Bhavani V. Sankar, and Raphael T. Haftka \\ University of Florida \\ Gainesville, Florida 32611 \\ Robert K. Goldberg \\ National Aeronautics and Space Administration \\ Glenn Research Center \\ Cleveland, Ohio 44135
}

\begin{abstract}
The objectives of this paper include identifying important architectural parameters that describe the $\mathrm{SiC} / \mathrm{SiC}$ five-harness satin weave composite and characterizing the statistical distributions and correlations of those parameters from photomicrographs of various cross sections. In addition, realistic artificial cross sections of a 2D representative volume element (RVE) are generated reflecting the variability found in the photomicrographs, which are used to determine the effects of architectural variability on the thermo-mechanical properties. Lastly, preliminary information is obtained on the sensitivity of thermo-mechanical properties to architectural variations. Finite element analysis is used in combination with a response surface and it is shown that the present method is effective in determining the effects of architectural variability on thermo-mechanical properties.
\end{abstract}

\subsection{Introduction}

Woven ceramic matrix composites (CMCs) are candidate materials for future hypersonic vehicle components such as thermal protection and aero-propulsion systems (Ref. 1). Evaluations of these materials indicate that there is considerable variability in their mechanical properties. A major feature contributing to this variability is the randomly distributed and shaped voids, which is caused by randomness in the architecture produced at various stages in manufacturing (Refs. 2 to 5). Some of the architectural variability contributing to the randomness includes constituent volume fractions, tow size, and tow spacing, tow shape, and ply shifting or tow nesting.

Conventional design methodologies compensate for the aforementioned uncertainties by use of a safety factor (estimated based on experience), which may not allow a designer to take full advantage of the composite properties because the details of the microstructure are not rigorously accounted for. More recently other methods of accounting for the uncertainties have been explored. Some of these methods include a multi-scale approach in which relationships are developed that link the lowest level (unidirectional composite) to the mid-level (woven composite), and finally to the highest level (laminated woven composite) (Ref. 6). While this approach may be effective in determining average mechanical properties, it does not explicitly account for the effects of non-uniform void size, void shape, void location, and other microstructural variations such as tow size which should not be neglected. The importance of accounting for these factors explicitly in woven CMCs has recently been studied in a qualitative sense (Ref. 7). However, there is still a need to account for these factors in a quantitative sense. Additional analytical approaches accounting for certain details such as waviness or constituent volume fractions have also been developed, but again they do not model porosity explicitly (Refs. 8 and 9). While these approaches may work very well for some woven composites, it is possible that they do not adequately represent woven composites containing very large non-uniform voids, like those observed in the composite currently being investigated. 
Models that include the variability at the constituent level combined with probabilistic techniques can be used to determine the variability in effective mechanical properties. The advantage of probabilistic techniques is that they account for variation in a realistic manner that may lead to a thorough representation of the material variability. Such approaches require complete characterization of uncertainties in the composite. Thus, there is a need to develop efficient methods to propagate the uncertainties from the primitive variables, e.g., fiber and matrix properties and porosity, to the response variables such as the stiffness of the composite material (Ref. 10). CMCs have been analyzed in a probabilistic manner in the past. However, the methods typically involved a degradation of matrix properties to account for voids, and variability in the microstructure was estimated, rather than rigorously quantified (Ref. 3). This assumption does not account for the size, shape, and the interaction of the voids with one another which can affect the mechanical properties, as was shown by Huang and Talreja for unidirectional fiber reinforced composites (Ref. 11). While voids are modeled explicitly for the study presented here, their wide range of variability is not. A detailed study of the effects of variable void size, shape, and distribution will be studied more completely in future work.

In this paper, a methodology is presented for modeling the variability in architectural parameters of 5HS CVI (five-harness satin weave, chemical vapor infiltrated) $\mathrm{SiC} / \mathrm{SiC}$ composite, using 2D micrographs of three cross sections to identify the important architectural parameters and their distributions. These are then used to perform Monte Carlo simulations of possible architectural variants. Finite element micromechanics simulations combined with the use of a response surface are then utilized to predict the variability in mechanical properties and understand its causes. The uncertainty is parameterized based on measurable variables within the architecture to gain an understanding of the causes of variation in the mechanical properties. The results from this study are used to determine the sensitivity of thermo-mechanical properties to several architectural parameters, as well as the expected distribution in mechanical properties due to these parameters.

\subsection{Characterization of the Composite}

\subsection{Geometric Parameterization and Model Assumptions}

The image in Figure 1 is a 3D representation of the weave for a 5HS unit cell. The composite has continuous Sylramic-iBN fiber tows ( 20 ends per inch) woven into a five-harness woven fabric preform in a $\left[0^{\circ} / 90^{\circ}\right]$ pattern. A silicon-doped boron nitride coating is deposited on the surface of the individual filaments in the tows. The fiber preform is then infiltrated with a CVI-SiC matrix which fills the tows and forms a thin matrix coating around the tow. The authors are simply using a material provided by a manufacturer for a demonstration of the methodology and did not chose the architecture.

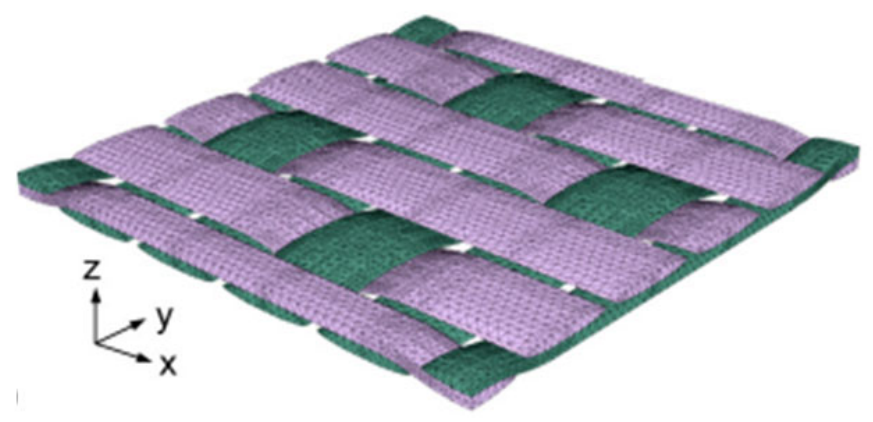

Figure 1.-3D finite element model of 5 harness satin weave (Ref. 7). 


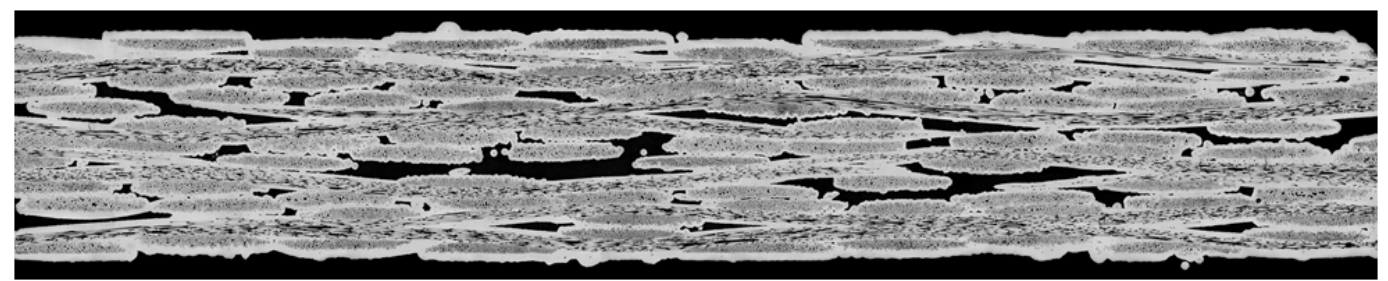

Figure 2.-2D cross section of the $\mathrm{SiC} / \mathrm{SiC}$ composite microstructure where the black interior represents voids. The black area at the top and bottom is blank space around the composite specimen (Ref. 7).

3

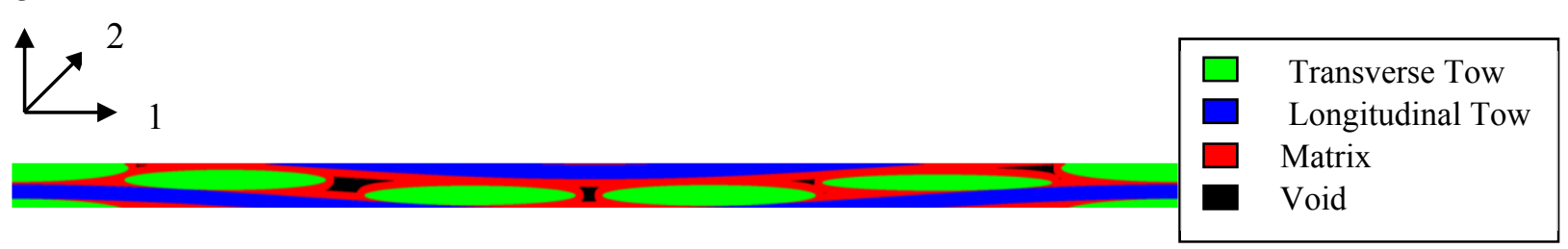

Figure 3.-2D Unit cell of $5 \mathrm{HS}$ composite.

The microstructure of the composite has been shown to have significant randomness, resulting in large variability in the mechanical properties. A 2D micrograph of one cross section of the composite, obtained by Goldberg, et al. is shown in Figure 2 (Ref. 7). The black areas in the interior of the cross section represent voids (the black area on the borders of the image are not voids), which vary in location, size, and shape. Other 2D cross sections are not identical to the one shown, but rather, exhibit different random distributions of the voids and the microstructural characteristics such as tow size, shape, and spacing. Therefore, some simplifying assumptions, explained in the following paragraphs, were made to develop an understanding of the composite at a basic level.

For this work, the focus was on modeling a representative volume element (RVE) of the 8 ply 5 HS composite in order to keep the size of the problem tractable while capturing the important statistical characteristics. Due to the large amount of variability, it is difficult to define an RVE in the traditional manner, in which the RVE is a statistically equivalent representation of the larger cross section. Preliminary work by the authors involved the use of only one unit cell (one ply), which consists of a weft tow crossing over four warp tows, as shown in Figure 3 (Ref. 12). The weave of one 2D unit cell consists of five elliptical transverse tows, and one longitudinal tow that follows a sinusoidal curve. The configuration of the unit cell is based on tow spacing in the in-plane and transverse directions ( $s$ and $\Delta Y$, respectively), transverse tow width $(w)$, transverse tow height $(h)$, longitudinal tow amplitude $(A)$, and longitudinal tow wavelength $(\lambda)$, as labeled in Figure 4. The in-plane tow spacing, tow width, and tow height are randomly assigned as described later. The longitudinal tow is a sine curved described by the equation

$$
Y=A^{*} \sin \left(\frac{2 \pi}{\lambda} X+\frac{\pi}{2}\right)
$$

where the longitudinal tow amplitude $(A)$ is $0.07 \mathrm{~mm}$ (obtained by estimation from micrographs), and the wave length $(\lambda)$ and position $(X)$ vary and are functions of the randomly prescribed tow width and tow spacings. The spacing in the transverse direction $(\Delta Y)$ also varies depending on the position, $X$, for each tow. For multiple stacked unit cells an additional variable called the tow offset is introduced. The tow offset can be defined as two unit cells being stacked on top of one another, and then shifted by a given tow length. This tow offset is also referred to as ply shifting. Figure 4 illustrates a tow offset of 2 . 

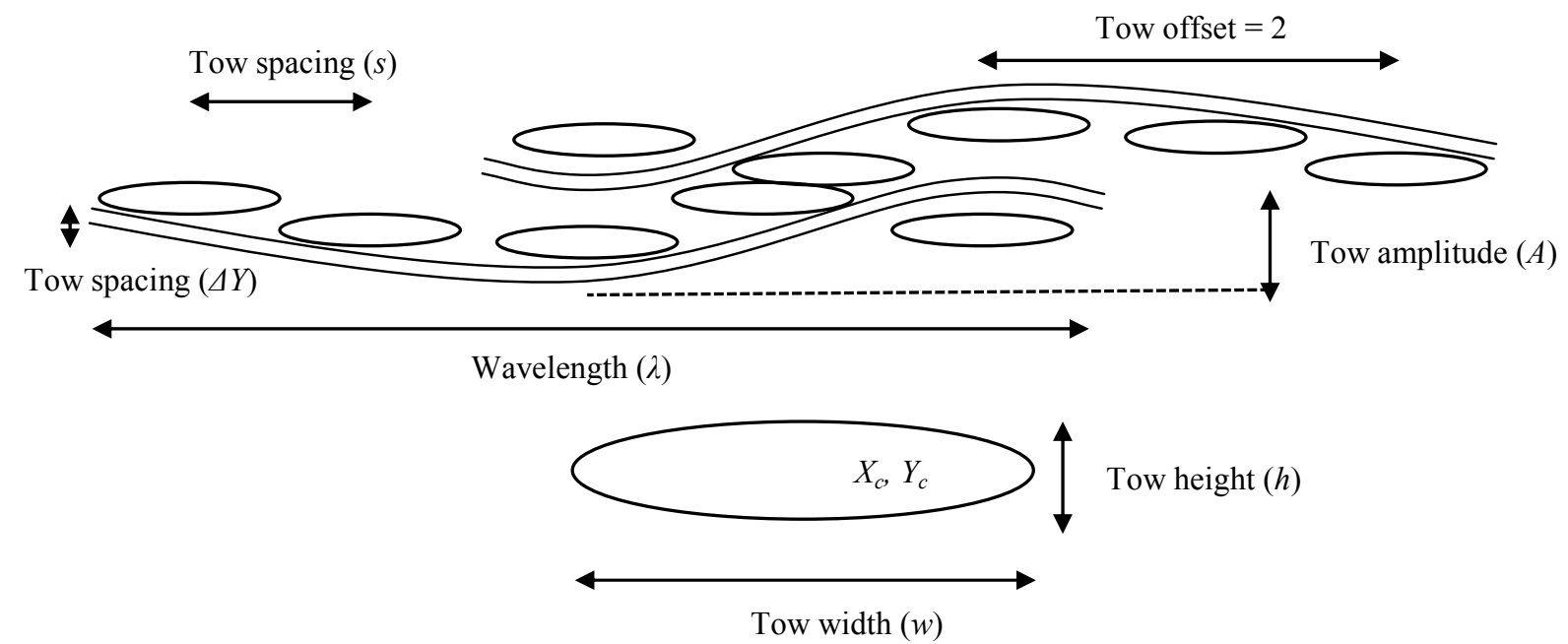

Figure 4.-Geometry of unit cell.

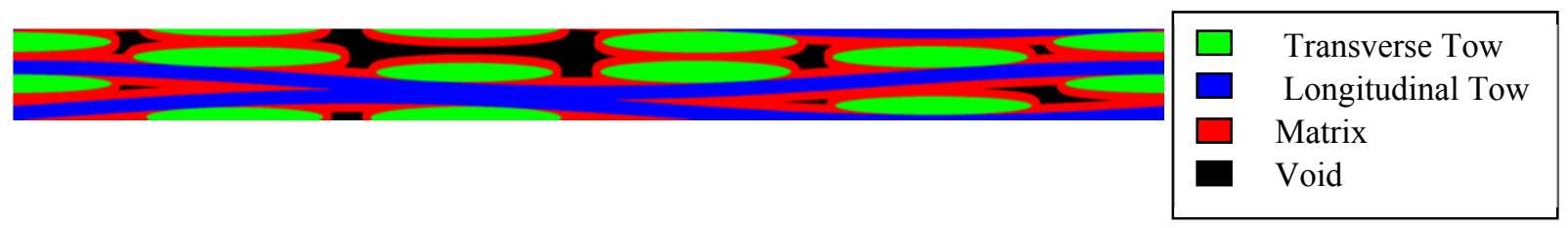

Figure 5.-Example of a randomly generated RVE.

After the tows are placed, the matrix is grown uniformly around the tows, until a prescribed matrix volume fraction is reached. While the non-uniform matrix distribution seen in Figure 2 is not captured precisely, the method approximates the manufacturing process of matrix deposition in that the voids generated are a result of the tow placement (Ref. 7). However, the unit cell neglected the presence of any ply shifting/tow nesting (uneven tow alignment as illustrated in Fig. 4) that is exhibited in the actual composite, resulting in artificial cross sections that did not realistically represent the void geometry. All voids were small and compact, as opposed to a few having a large aspect ratio. The ply shifting is one cause of the voids with large aspect ratios.

In order to capture the ply shifting a larger RVE was modeled, made up of two unit cells with a uniform tow offset or shifting for all RVEs. With more plies, the ply shifting would change within each layer. This variability in shifting is currently being neglected since it cannot be rigorously quantified in the same manner as the other variables being investigated. The 2D representation of a 5HS RVE is shown in Figure 5. The figure is a result of using two unit cells, with one flipped upside down (as done by the material manufacturer), and shifted by one tow length.

Another assumption was made in regards to modeling the composite in 2D as opposed to 3D. One important goal was to explicitly represent the voids in finite element analysis based on where they naturally occur due to variation in the weave architecture. In a recent survey of available 3D modeling tools, it was found that there are no tools with a completely generalized capability that would be suitable for the current modeling task of generating a matrix with naturally occurring voids as a result of perturbations in the weave geometry (Ref. 13). A 2D plane strain representation of the woven composite is not completely accurate. However, since the purpose of the paper is to gather information on modeling the architectural variation and to determine how the variation affects the thermo-mechanical properties in a general sense, a 2D assumption was deemed appropriate (Ref. 7). In addition, the resulting mechanical properties due to $2 \mathrm{D}$ analyses discussed in the paper do not deviate significantly from limited experimental results available for a similar composite (Ref. 14). 


\subsection{Statistical Distributions and Correlations}

The parameters chosen to be randomly varied were selected based on availability of statistical data, and whether or not there was significant variation in the parameter. Image processing techniques were used to extract information about the tows (Ref. 7). The geometric parameters for which statistical data was available were transverse tow width $(w)$, transverse tow height $(h)$, and transverse tow spacing in the longitudinal direction $(s)$, as labeled in Figure 4. The data used can be found in the Electronic Supplementary Data (Ref. 15). Other architectural parameters, such as tow spacing in the through thickness direction and longitudinal tow amplitude are either dependent on the variables used, or were approximated based on visually fitting the geometry to the cross sections. The variables that do not yet have statistical data (like crimp angle) were held constant.

The random generation of the variables was based on the statistical data in three different cross sections (similar to that shown in Fig. 2), resulting in approximately 225 data points (each tow provided a data point) (Ref. 7). While the data from the three cross sections cannot provide accurate statistical distributions, the goal is to explore how the variability should be modeled. For this purpose, the data is sufficient. However, to calculate accurate probabilities, more data would be necessary. It was found that the tow spacing and tow width fit best (according to the lowest standard error in the fit) to a normal distribution. Plots of the empirical cumulative distribution functions (CDF) and the normal cumulative distribution functions are displayed in Figures 6 and 7. In Figure 8, both a Weibull and Normal CDF are plotted with the empirical CDF. By visual inspection they both fit closely. The square error, computed by

$$
\text { Error }=\sum_{i}^{\text {\#Data Points }}\left(p_{\text {data }, i}-p_{C D F, i}\right)^{2}
$$

where $p_{\text {data }}$ is the cumulative probability at an individual data point and $p_{C D F}$ is the cumulative probability for a given distribution such as normal or Weibull, was found to be 0.0013 and 0.0027 for the Weibull and normal distributions, respectively. Since correlation is taken into account (as described in the next paragraph) it is more convenient to use a normal distribution for all variables, and the error introduced by using this distribution is very small. The parameters of the distributions are given in Table 1.

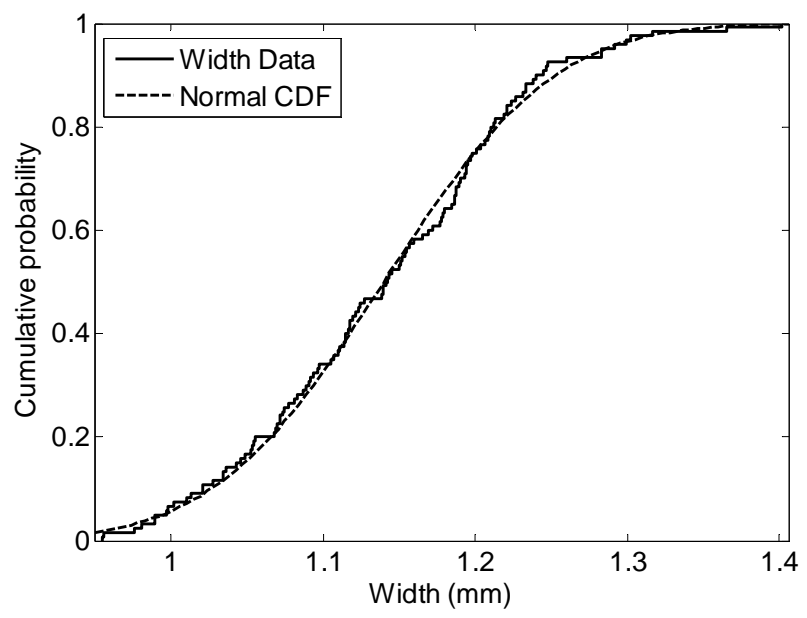

Figure 6.-Empirical and normal CDF for tow width. 


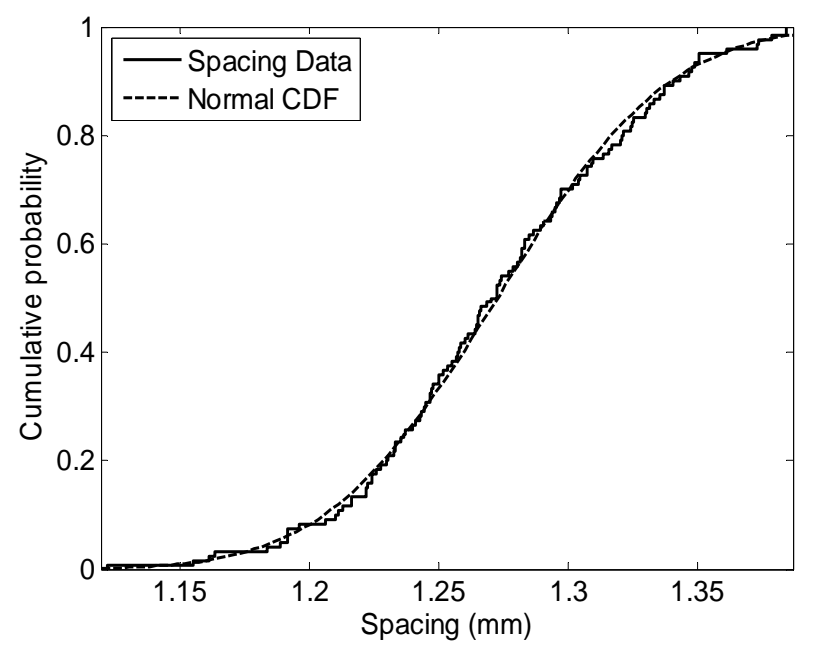

Figure 7.-Empirical and normal CDF for tow spacing.

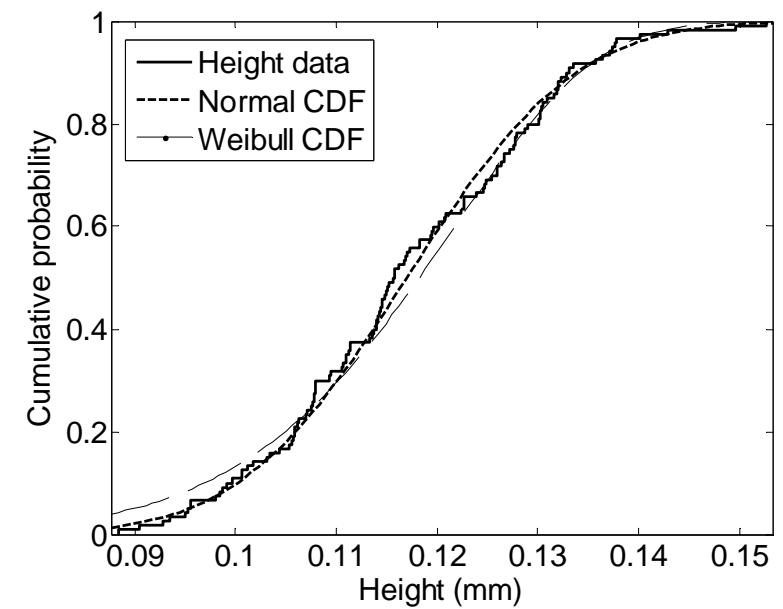

Figure 8.-Empirical, normal, and weibull CDF for tow height.

TABLE 1.-SUMMARY OF VOLUME FRACTIONS AND GEOMETRIC CHARACTERISTICS FOR 3 REAL CROSS SECTIONS

[For the cases in which there are values in parentheses, the value in in parentheses is the standard deviation and the other value is the average for the specific cross section listed.]

\begin{tabular}{|l|c|c|c|c|c|c|}
\hline & \% Void & \% Matrix & \% Tow & $\begin{array}{c}w, \\
\mathrm{~mm}\end{array}$ & $\begin{array}{c}s, \\
\mathrm{~mm}\end{array}$ & $\begin{array}{c}h, \\
\mathrm{~mm}\end{array}$ \\
\hline Cross section 1 & 3.2 & 33.8 & 63.0 & $1.14(0.08)$ & $1.27(0.05)$ & $0.12(0.01)$ \\
\hline Cross section 2 & 4.8 & 32.4 & 62.8 & $1.15(0.08)$ & $1.27(0.06)$ & $0.12(0.01)$ \\
\hline Cross section 3 & 3.5 & 32.6 & 63.9 & $1.14(0.08)$ & $1.27(0.05)$ & $0.12(0.01)$ \\
\hline Mean & 3.8 & 32.9 & 63.2 & 1.14 & 1.27 & 0.12 \\
\hline St. Dev. & 0.9 & 0.8 & 0.6 & 0.08 & 0.05 & 0.01 \\
\hline
\end{tabular}


An issue that further complicates the problem is that the variables not only vary between the cross section, but they have a variation within each cross section as well. If each tow in the cross section is given a unique geometry, it is important to consider correlation (a measure of the strength of the linear relationship between two variables) between the variables in order to avoid producing unrealistic cross sections. Therefore, each transverse tow is assigned an individual, but correlated, tow width, tow height, and tow spacing. Since there are five tows in the RVE, this results in a total of fifteen variables (five tow widths, five tow heights, and five tow spacings). Using correlated parameters ensured that inherent architecture variation due to the manufacturing process would be accounted for and the generation of unrealistic cross sections would be minimized.

\subsection{Generation of Artificial Cross Sections}

The number of cross sections chosen for the finite element analysis was based on how much data is needed for the potential response surfaces (discussed in a following section). For the finite element analysis, which is used to determine the magnitude of thermo-mechanical property variability, 38 artificial cross sections were generated. The number of cross sections necessary depends on the order of the polynomial response surface and is explained in Section 3.2. In order to determine the statistical distribution of mechanical properties, 1,000 artificial cross sections were randomly generated. The 1,000 artificial cross sections were generated to determine the constituent volume fractions for each one. However, the mechanical properties from these cross sections will be determined with a response surface, rather than analyzing each one individually. A typical artificial cross section is shown in Figure 5.

A summary of the characteristics of the three sample cross sections from which the statistics were obtained is presented in Table 1. For the individual cross sections, the mean and standard deviation of width, spacing and height is provided, with standard deviations in parentheses. Tables 2 and 3 are characteristics of the artificial cross sections. The volume fractions and geometric parameters of tow width $(w)$, tow spacing $(s)$, and tow height $(h)$ from the actual composite and artificial cross sections are in good agreement.

The correlation coefficients (based on 24 data points) of the significantly correlated parameters (correlation coefficient is greater than 0.4) are displayed in Table 4. The statistical significance is in parentheses (the likelihood that the correlation coefficient arose by chance). For example, spacing between the first and second tow (spacing 1) and spacing between the third and fourth tow (spacing 3 ) have a correlation coefficient of -0.47 . This can be interpreted by saying that when spacing 1 increases, spacing 2 decreases, but not necessarily in a one to one ratio. It is likely that the spacing and width have some degree of correlation because when the composites are manufactured they are restricted to a certain width. Therefore, depending on the tow sizes, the spacing has to adjust to accommodate for all of the tows.

TABLE 2.-SUMMARY OF VOLUME FRACTIONS AND GEOMETRIC CHARACTERISTICS FOR 38 ARTIFICIAL CROSS SECTIONS

\begin{tabular}{|l|c|c|c|c|c|c|}
\hline & \% Void & \% Matrix & \% Tow & $\begin{array}{c}w, \\
\mathrm{~mm}\end{array}$ & $\begin{array}{c}s, \\
\mathrm{~mm}\end{array}$ & $\begin{array}{c}h, \\
\mathrm{~mm}\end{array}$ \\
\hline Mean & 4.2 & 32.9 & 62.9 & 1.15 & 1.27 & 0.12 \\
\hline St. Dev. & 0.7 & 0.5 & 0.9 & 0.09 & 0.05 & 0.01 \\
\hline
\end{tabular}

TABLE 3.-SUMMARY OF VOLUME FRACTIONS AND GEOMETRIC CHARACTERISTICS FOR 1000 ARTIFICIAL CROSS SECTIONS

\begin{tabular}{|l|c|c|c|c|c|c|}
\hline & \% Void & \% Matrix & \% Tow & $\begin{array}{c}w, \\
\mathrm{~mm}\end{array}$ & $\begin{array}{c}s, \\
\mathrm{~mm}\end{array}$ & $\begin{array}{c}h, \\
\mathrm{~mm}\end{array}$ \\
\hline Mean & 4.2 & 32.8 & 63.0 & 1.14 & 1.27 & 0.12 \\
\hline St. Dev. & 0.7 & 0.5 & 0.8 & 0.09 & 0.05 & 0.01 \\
\hline
\end{tabular}


TABLE 4.-COMPARISON OF CORRELATION COEFFICIENTS FOR REAL CROSS SECTIONS (FIRST VALUE) AND ARTIFICIAL CROSS SECTIONS (SECOND VALUE)

[The value in parentheses is the statistical significance.]

\begin{tabular}{|l|c|c|c|c|c|}
\hline & Spacing 3 & Spacing 4 & Spacing 5 & Width 3 & Width 5 \\
\hline Spacing 1 & $\begin{array}{c}-0.47,-0.44 \\
(0.02)\end{array}$ & & & & \\
\hline Spacing 2 & $\begin{array}{c}-0.42,-0.41 \\
(0.05)\end{array}$ & & & & $\begin{array}{c}0.41,0.45 \\
(0.05)\end{array}$ \\
\hline Spacing 3 & & $\begin{array}{c}0.45,0.42 \\
(0.05)\end{array}$ & & & \\
\hline Spacing 4 & & & $\begin{array}{c}0.60,0.58 \\
(0.01)\end{array}$ & & \\
\hline Width 1 & & & & $0.56,0.58$ & $0.41,0.43$ \\
& & & & & $0.01)$ \\
\hline Width 3 & & & & & $0.44,0.46$ \\
& & & $0.05)$ \\
\hline
\end{tabular}

\subsection{Analysis Methods}

\subsection{Finite Element Analysis}

The RVEs were generated as red, green, and blue images with a Python code ${ }^{1}$ (e.g., Fig. 5), which were then meshed with open source software, OOF2 (Ref. 16). OOF2 allows the user to import an image and define the different materials by color selection. It then creates a mesh of a desired size with homogenous elements (each element has only one material associated with it). This mesh was then imported into the commercial software, ABAQUS, for finite element analysis (Ref. 17). A combination of linear triangular and quadrilateral plane strain elements was used. The material properties assigned were determined by Goldberg, et al. using standard micromechanics formulations for unidirectional composites and are shown in Table 5 (Ref. 7). While there may be variation in the thermo-mechanical properties of the tows, it is thought to contribute less to the overall variability than the architecture. Therefore the thermo-mechanical properties of the tows are held constant. Since the RVE is modeled in 2D, the longitudinal and transverse tows were treated as separate materials. The yarn/matrix interphase is not explicitly modeled in the present study. The tows are modeled as homogenous orthotropic materials, with resultant properties based on the fiber, matrix, voids, and interphase in the tows. The matrix was assumed to be an isotropic material.

TABLE 5.-CONSTITUENT MATERIAL PROPERTIES

\begin{tabular}{|l|c|c|c|}
\hline & Transverse tow & Longitudinal tow & Matrix \\
\hline$E_{1}[\mathrm{GPa}]$ & 106 & 259 & 420 \\
\hline$E_{2}[\mathrm{GPa}]$ & 259 & 106 & 420 \\
\hline$E_{3}[\mathrm{GPa}]$ & 106 & 106 & 420 \\
\hline$v_{12}$ & 0.21 & 0.21 & 0.17 \\
\hline$v_{13}$ & 0.21 & 0.18 & 0.17 \\
\hline$v_{23}$ & 0.18 & 0.21 & 0.17 \\
\hline$G_{12}[\mathrm{GPa}]$ & 41.4 & 41.4 & 179.5 \\
\hline$G_{13}[\mathrm{GPa}]$ & 41.4 & 42.5 & 179.5 \\
\hline$G_{23}[\mathrm{GPa}]$ & 42.5 & 41.4 & 179.5 \\
\hline$\alpha_{1}\left[10^{-6} /{ }^{\circ} \mathrm{C}\right]$ & 4.6 & 4.6 & 4.7 \\
\hline$\alpha_{2}\left[10^{-6} /{ }^{\circ} \mathrm{C}\right]$ & 4.6 & 4.6 & 4.7 \\
\hline$\alpha_{3}\left[10^{-6} /{ }^{\circ} \mathrm{C}\right]$ & 4.6 & 4.6 & 4.7 \\
\hline
\end{tabular}

\footnotetext{
${ }^{1}$ Python is an open source object-oriented programming language.
} 
A finite element analysis based micromechanics approach was used to determine the effective elastic moduli, Poisson's ratios and coefficients of thermal expansion (CTEs) of the RVE. The constitutive equations of the composite can be written as

$$
\{\sigma\}=\underset{6 \times 6}{[C]}\left\{\begin{array}{l}
\{\varepsilon\}-\{\alpha\} \Delta T \\
6 \times 1 \quad 6 \times 1
\end{array}\right\}
$$

where the stresses and strains are macroscopic or volume averaged quantities, $C$ is the stiffness matrix, $\alpha$ is the matrix of CTEs and $\Delta T$ is the temperature difference measured from the reference temperature. A summary of micromechanical analysis procedures is given below.

Periodic boundary conditions are applied such that one of the macro strains is non-zero and all other strains and $\Delta T$ are zero. The macro-stresses are calculated by averaging the micro- stresses in the RVE. Using the six macro-stresses one can determine the first column of $C$. The procedure is repeated for the other five macro stains to calculate the entire $C$ matrix. From $C$ one can calculate the elastic constants using the relations of the type

$$
\begin{aligned}
& {[C]^{-1}=[S]=\left[\begin{array}{ccc}
S_{11} & \ldots & S_{16} \\
\ldots & \ldots & S_{26} \\
S_{61} & \ldots & S_{66}
\end{array}\right]} \\
& S_{11}=\frac{1}{E_{1}}, S_{12}=\frac{v_{21}}{E_{2}}, S_{66}=\frac{1}{G_{12}}, \text { etc. }
\end{aligned}
$$

In order to determine the CTEs the periodic boundary conditions are applied such that all macrostrains are suppressed and a known $\Delta T$ is applied to the RVE. Additional inputs to the finite element analysis are the CTEs of the tow and matrix phases. By substituting the macro-stresses in Equation (1) one can solve for the CTEs as

$$
\{\alpha\}=-\frac{1}{\Delta T}[C]^{-1}\{\sigma\}=-\frac{1}{\Delta T}[S]\{\sigma\}
$$

Since plane elements in the 1-3 plane were used for the FE analysis slight modification of the procedures were required. Using plane strain elements the boundary conditions corresponding to macrostrains $\varepsilon_{1}, \varepsilon_{3}$, and $\gamma_{13}$ could be easily implemented. The generalized plane strain condition could also be used for the case $\varepsilon_{2}=1$. The transverse shear strains $\gamma_{12}=1$ and $\gamma_{32}=1$ cannot be implemented using the plane strain elements. Plate elements with only $u_{2}$ degree of freedom in the 2-direction were used for the two transverse shear strain cases (Ref. 18). Since ABAQUS does not provide the transverse shear stress for plate elements, the displacement at each node combined with shape functions was used to extract the stress in each element manually.

\subsection{Response Surface}

In order to quantify the statistical distribution of thermo-mechanical properties to specific variability in the architecture, many analyses are often necessary (depending on desired accuracy). While the computational time of the individual analyses mentioned previously is not unmanageable, the mesh generation is very time consuming ( $\sim 40 \mathrm{~min}$. per model). One thousand models were necessary for the work in this paper, necessitating a method in which many analyses could be performed in a short amount of time. 
When it is desired to determine the response at a large number of data points, it is typical to perform analyses at a small set of data points, which are then fit with a polynomial response surface. For this work, a linear polynomial response surface was used, necessitating $2(n+1)$ analyses where $n$ is the number of variables, and twice the minimum amount of variables $(n+1)$ was used to improve the accuracy of the response surface. The relationship between the variables and the thermo-mechanical properties is given by

$$
\text { response }=c_{1} x_{1}+c_{2} x_{2}+\ldots+c_{n} x_{n}+c_{n+1}
$$

where $c_{n}$ is the coefficient and $x_{n}$ is the variable. The coefficients indicate the sensitivity of the response to a given variable.

In the current work, 15 random variables were chosen, as explained in a previous section, in addition to constituent volume fractions. Previous work by the authors demonstrated the importance of including the volume fractions (Ref. 12). As shown later in this paper, volume fractions carry a heavier weight than the architectural variations in the influence of certain mechanical properties, which is important since volume fractions are typically easier to work with. For a linear response surface in 18 variables, 38 high fidelity models are necessary (one analysis for each constant). For the selection of the variable values of the 38 FEA models, Latin Hypercube Sampling was used. This technique ensures representation of a realistic variability by generating non-repetitive samples that are evenly distributed in the design space.

\subsection{Results and Discussion}

\subsection{Finite Element Analysis}

The goal was to model the variability in the thermo-mechanical properties of the real cross sections by varying the architectural properties in an RVE. The tensile moduli of the full cross sections are provided in Table 6 for comparison to the RVE analysis. The three full cross sections analyzed are based on actual cross sectional images of a $5 \mathrm{HS} \mathrm{SiC/SiC} \mathrm{composite.} \mathrm{The} \mathrm{thermo-mechanical} \mathrm{properties} \mathrm{of} 38$ artificial cross sections were determined with finite element analysis as described in the previous section. The mean and standard deviation of the thermo-mechanical properties are shown in Table 7. It is important to note that values in the 2-direction, such as $E_{2}$, may be lacking in accuracy due to the 2-D assumption. In reality the behavior of $E_{2}$ would be similar to that of $E_{1}$ due to the balanced weave of the actual composite. The in-plane stiffness $E_{1}$ and shear stiffness $G_{12}$ compares well (less than 10 percent error) to experimental results found in the literature on a similar material, melt infiltrated CVI 5HS $\mathrm{SiC} / \mathrm{SiC}$ composite (Ref. 14). The material has a smaller void volume fraction which is the likely cause of the discrepancy. The transverse stiffness $E_{3}$ is over-predicted by approximately 33 percent compared to approximate experimental results, which is likely related to the use of constant ply shifting, as explained later. The response surface results presented in Table 7 are explained in the following section. Note that the variability in RVE properties is smaller than that exhibited by the full cross sections. An explanation for the discrepancy is given in Section 4.3.

While the full extent of the variability of the full cross sections is not captured, some initial observations can be drawn from the RVE results. It is known that voids have a significantly more detrimental effect on the out of plane moduli than the in-plane moduli for varying void content as well as for flat shapes (Ref. 11). Therefore it is not surprising that with varying geometry, which inherently alters the void volume fraction, the coefficient of variation in the through thickness modulus is almost three times that of the coefficient of variation in in-plane modulus. Huang and Talreja (Ref. 11) also observed that the voids would have the most significant impact in the out-of-plane shear modulus $\left(G_{13}\right)$, which is also observed here. While the out-of-plane CTE is smaller than that of the in-plane CTE, the coefficients of thermal expansion were shown to be insensitive to the variations in architectural parameters. This is due to the fact that the coefficients of thermal expansion of the constituents are approximately the same. If the coefficients of thermal expansion were drastically different between the constituents, there would be more variability due to architectural variation and voids. 


\subsection{Response Surface}

After completing the finite element analysis, the mean values and the approximate variability associated with them is determined. Fitting a response surface to the data provides two additional pieces of information. First, the response surface indicates the magnitude of the effect each variation has on the property being examined (based on the magnitude of the coefficients). Secondly, the response surface allows the statistical distribution of the properties to be estimated (for example, Normal or Weibull distributions).

Several options were explored regarding which variables should be used in the response surface. Initial work by the authors involved fitting the response surface to every architectural variation required for the formation of the RVE ( 5 tow widths, 5 tow heights, and 5 tow spacings), as well as the volume fractions (Ref. 12). However, this does not provide useful information since each individual tow parameter cannot be controlled by a manufacturer. Instead, the individual variations in tow parameters will provide information about the amount of variability, but it is more practical to discuss the architectural variations in an average sense. Therefore, the response surface variables selected were: (1) average tow width, (2) average tow spacing, (3) average tow height, (4) tow volume fraction, (5) void volume fraction, (6) standard deviation in the width, (7) standard deviation in the spacing, and (8) standard deviation in the height. The matrix volume fraction was not used since it is directly dependent on the tow and void volume fractions. The use of the average tow properties in the fit provides general information about how much tow properties affect the mechanical properties on average. Using the standard deviation of the tow properties in each RVE gives additional information on how much the variation in tow properties within each RVE affects the mechanical properties.

After selecting the pertinent variables, a linear polynomial response surface was fit to the finite element results. One response surface was created for each mechanical property. A response surface was not generated for the CTE since the variability was insignificant. The sensitivity of each modulus to certain variables (labeled as "coefficient") is displayed in Figure 9. The numbers are the coefficients for each response surface. Only coefficients with a test-statistic greater than 2 were used. Also, note that since some parameters are correlated, one coefficient may be dependent on another. For example the average tow width is related to the tow volume fraction. The response surface, however, does not directly account for the dependencies which should be considered upon interpreting the results. The moduli were most sensitive to the average tow width, average tow spacing, tow volume fraction, and void volume fraction. There was minor sensitivity to the amount of variability in tow spacing due to the effect that it has on the void shape and size. The tow width, tow spacing, and variation in the spacing was most important in determining the in-plane modulus $\left(E_{1}\right)$. The modulus $E_{2}$, which theoretically should be equivalent to $E_{1}$, was primarily dependent on the volume fractions (specifically, the void volume fraction). The discrepancy is due to the fact that in a generalized plane strain model, equivalent materials also have equivalent stresses. Therefore, the modulus is related to the quantity of each material. The outof-plane modulus $\left(E_{3}\right)$ is most strongly dependent on tow volume fraction. This is not to say that it is the only important factor, but rather with the current modeling methodology it is shown to be the most impactful. As discussed later in the paper, it is hypothesized that the void size, shape, and alignment plays an even larger role than solely the volume fraction. Note that either tow volume fraction or void volume fraction can be used to determine the modulus, but not both, because they are dependent on one another. The shear moduli $\left(G_{12}, G_{13}\right.$, and $\left.G_{23}\right)$ are dependent on the tow width, tow spacing, and tow volume fraction. This is likely due to the effects spacing and tow width has on the voids.

The response surfaces were then used to calculate the mechanical properties of 1,000 artificial cross sections. The results from the response surfaces are presented in Table 7. The mean values agree well with the finite element results, and the standard deviations are slightly smaller. The difference in standard deviations is due to the fact that when fitting a polynomial response surface, noise is filtered, thereby decreasing the variability. It was found that the mechanical properties were normally distributed. 


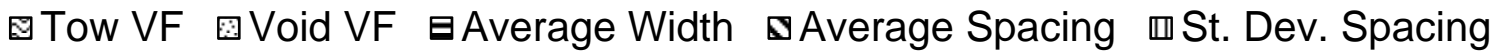

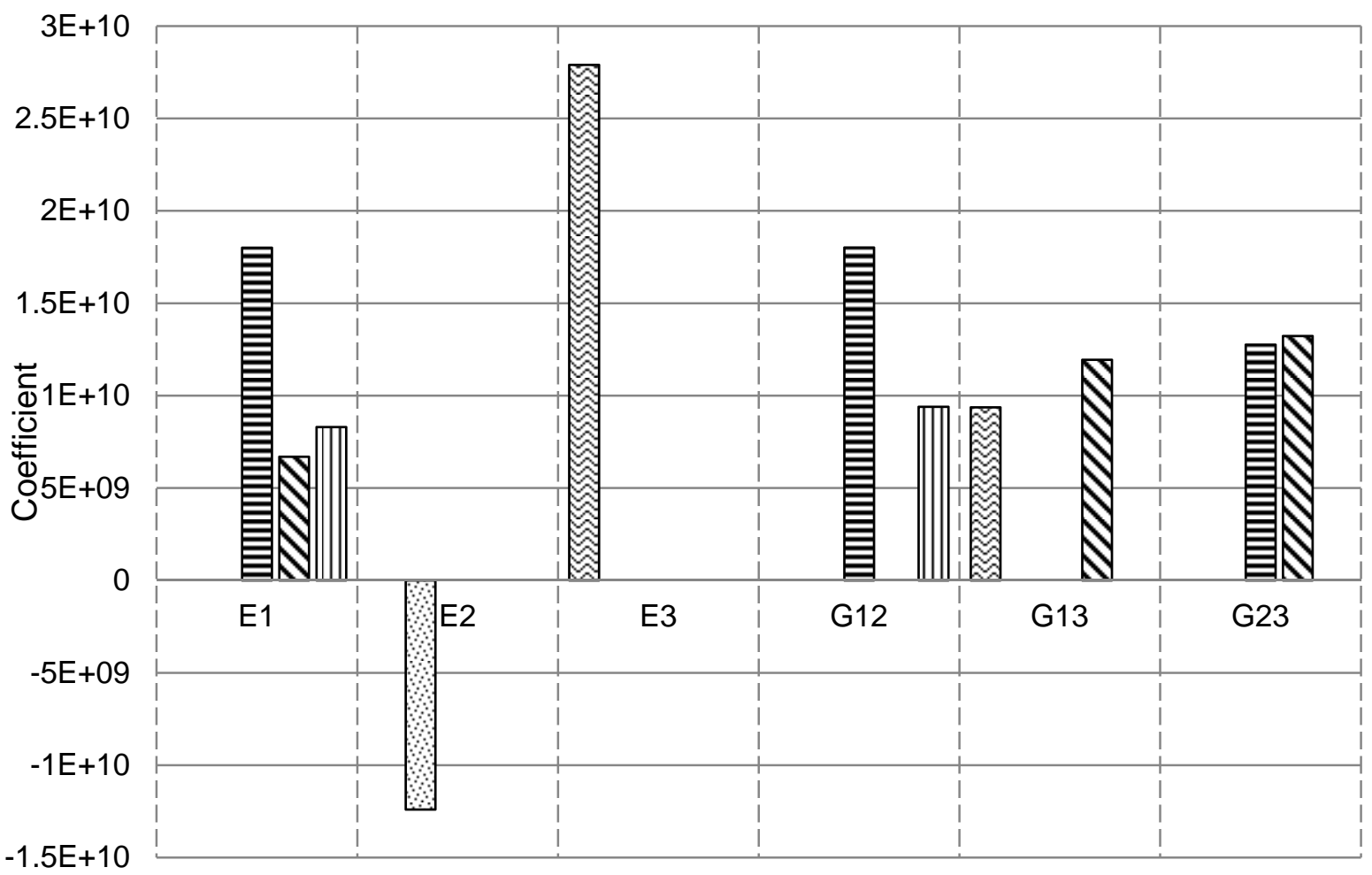

Figure 9.-Dependencies of moduli on architectural variability and volume fractions.

TABLE 6.-FEA RESULTS OF FULL CROSS SECTIONS

\begin{tabular}{|l|c|c|c|c|c|}
\hline & \% Void & \%Tow & \% Matrix & $E_{1}[\mathrm{GPa}]$ & $E_{3}[\mathrm{GPa}]$ \\
\hline Cross section 1 & 3.2 & 63.0 & 33.8 & 237 & 103 \\
\hline Cross section 2 & 4.8 & 62.8 & 32.4 & 227 & 77 \\
\hline Cross section 3 & 3.5 & 63.9 & 32.6 & 234 & 51 \\
\hline
\end{tabular}

TABLE 7.-SUMMARY OF FEA AND RESPONSE SURFACE RESULTS

\begin{tabular}{|l|c|c|c|c|}
\hline & \multicolumn{2}{|c|}{ Finite element analysis results } & \multicolumn{2}{c|}{ Response surface results } \\
\hline & Mean & St. Dev & Mean & St. Dev \\
\hline$E_{1}[\mathrm{GPa}]$ & 231.0 & 5.0 & 230.4 & 3.6 \\
\hline$E_{2}[\mathrm{GPa}]$ & 259.9 & 1.9 & 260.0 & 1.9 \\
\hline$E_{3}[\mathrm{GPa}]$ & 105.8 & 6.2 & 106.2 & 4.4 \\
\hline$v_{12}$ & 0.174 & 0.005 & 0.174 & 0.003 \\
\hline$v_{13}$ & 0.202 & 0.004 & 0.201 & 0.003 \\
\hline$v_{23}$ & 0.123 & 0.006 & 0.123 & 0.005 \\
\hline$G_{12}[\mathrm{GPa}]$ & 74.5 & 5.2 & 74.1 & 3.1 \\
\hline$G_{13}[\mathrm{GPa}]$ & 20.6 & 3.6 & 20.4 & 2.3 \\
\hline$G_{23}[\mathrm{GPa}]$ & 44.8 & 1.7 & 44.9 & 0.9 \\
\hline$\alpha_{1}\left[10^{-6} /{ }^{\circ} \mathrm{C}\right]$ & 4.65 & 0.001 & --- & --- \\
\hline$\alpha_{2}\left[10^{-6} /{ }^{\circ} \mathrm{C}\right]$ & 4.65 & 0.001 & --- & --- \\
\hline$\alpha_{3}\left[10^{-6} /{ }^{\circ} \mathrm{C}\right]$ & 4.62 & 0.001 & --- & \\
\hline
\end{tabular}




\subsection{Comparisons of RVE to Full Cross Sections}

The results from the RVEs were compared to finite element results of the cross sections presented in Table 6 from which the data was taken (Ref. 7). It is clear that there is significantly variability in the outof-plane modulus $E_{3}$, and it is not directly correlated to volume fractions. The comparison of the full cross sections to the current RVE analysis reveals that the variability in the RVE models is not capturing the variability exhibited in the full cross sections.

One variable that the present RVE analysis neglected was variation in ply shifting. A shifting of one tow offset was applied for each RVE, rather than allowing it to be variable. Previous work by Woo and Whitcomb (Ref. 19) and Woo, Suh, and Whitcomb (Ref. 20) showed that tow offset (a bi-product of ply shifting) has a significant effect on some mechanical properties. In order to determine if neglecting ply shifting was a cause of the smaller variability in the RVEs as compared to the full cross sections, one RVE was used and assigned four different tow offsets. The magnitude of the tow offset is defined by assuming initial perfectly aligned tows or unit cells, then prescribing one unit cell to be offset by a certain fraction of a tow width. The results are summarized in Table 8. Note that there are small changes in volume fraction due to a small allowance of tow overlap in order to maintain a constant ply thickness. The variation in the shifting affects the out-of-plane modulus drastically. The standard deviation in the out-of-plane modulus for one cross section with ply shifting variation is 15 percent of the mean, as opposed to a standard deviation of approximately 5 percent of the mean for all architectural variability. The variability in ply shifting also decreases the average computed value of the modulus also.

A visual assessment of the voids in Figures 10 to 12 provides insight into the increased variability in the moduli due to shifting. The RVE with the tow offset of one tow has one void with a large aspect ratio, and several that are square in shape. The RVE in Figure 11 with a tow offset of 4.5 has three voids with an aspect ratio of the same order as the RVE in Figure 10. The cross section in Figure 12 has several voids with large aspect ratios distributed throughout the composite. This phenomenon is represented in the RVE in Figure 11.

It can be concluded that accounting for variability in ply shifting may capture the variability exhibited by the full cross sections in a more accurate manner than varying the tow width, tow spacing, and tow height alone. However, since the void volume fraction is also varying in the shifted cross sections examined, it cannot be said that the shifting alone is the cause of the variability. Future work will investigate the effects of ply shifting and attempt to precisely quantify the effect of void distribution and architecture on the mechanical properties.

TABLE 8.-RESULTS DUE TO SHIFTING VARIATION

\begin{tabular}{|c|c|c|c|c|c|}
\hline $\begin{array}{c}\text { Shifting } \\
\text { (tow offset) }\end{array}$ & \% Void & $\%$ Tow & $\%$ Matrix & $E_{1}[\mathrm{GPa}]$ & $E_{3}[\mathrm{GPa}]$ \\
\hline 1.00 (current RVE) & 4.4 & 63.1 & 32.6 & 224 & 106 \\
\hline 0.75 & 4.8 & 62.6 & 32.6 & 221 & 92 \\
\hline 2.50 & 5.5 & 61.6 & 32.9 & 231 & 82 \\
\hline 3.25 & 4.3 & 62.9 & 32.8 & 234 & 89 \\
\hline 4.50 & 5.9 & 61.6 & 32.6 & 218 & 70 \\
\hline
\end{tabular}

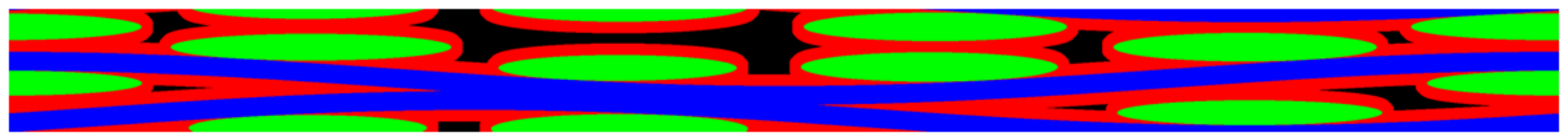

Figure 10.-RVE with tow offset equal to 1.0.

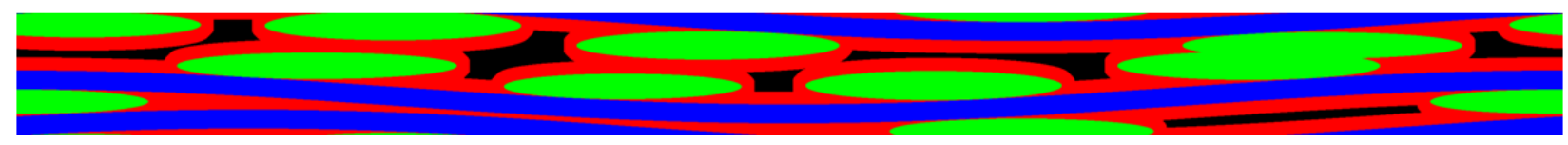

Figure 11.--RVE with tow offset equal to 4.5 . 


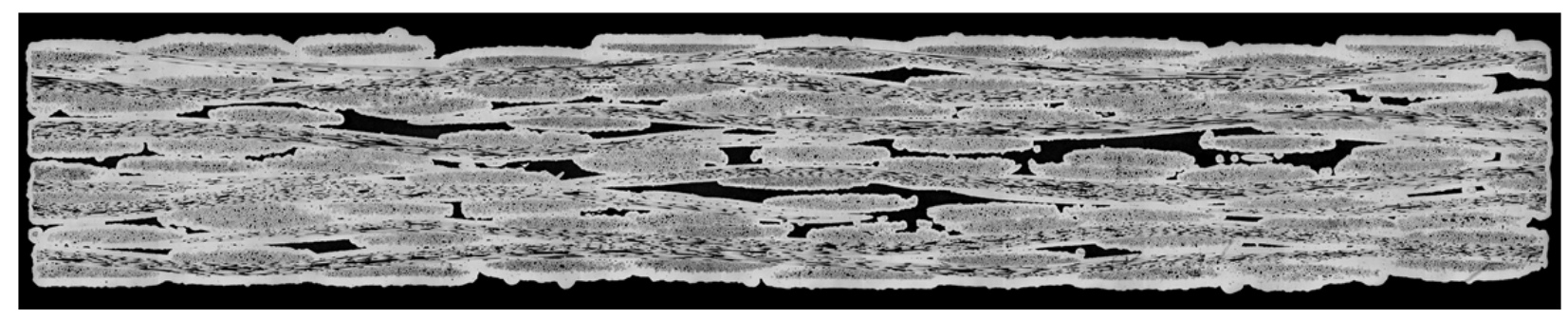

Figure 12.-Cross section 2.

\subsection{Conclusions}

The goal of this work was to select an RVE with architectural parameters that could be varied to effectively represent the variation in the properties of $\mathrm{SiC} / \mathrm{SiC}$ composite, while also gaining an understanding of which architectural parameters were influential in determining the variability in mechanical properties. The method of artificially generating cross sections by using statistical information from the micrographs of actual composite cross sections works well. The statistics of the real and artificially generated cross sections are in agreement.

The RVE was characterized by varying tow widths, heights, and spacing, resulting in variability of 2 to 6 percent of the mean for normal moduli and 4 to 17 percent of the mean for shear moduli. A negligible amount of variability was found for the CTE, due to a lack of CTE mismatch in the constituents. The variability was highest for the out-of-plane tensile modulus $\left(E_{3}\right)$, out-of-plane shear modulus $\left(G_{13}\right)$, and in-plane shear modulus $\left(G_{12}\right)$. The variability in mechanical properties was due predominantly to tow width, tow spacing, and volume fractions. This type of information may be useful if it is desired to model thermo-mechanical property variability in homogenized models at larger scales. If it is known that certain architectural features exist in part of a component, mechanical properties can be altered in that region to reflect the effects of those features.

FEA analysis of real composite cross sections revealed that there is more variability present than the variability predicted by the RVE with uniform ply shifting chosen. It is hypothesized that the variability in ply shifting should not be neglected since it may contribute to a significant portion of the variability. Future work will include a study of the effects of ply shifting on the voids' shape and size, with an attempt to predict the moduli based on the voids' characteristics.

\section{References}

1. H. Ohnabe, S. Masaki, M. Onozuka, K. Miyahara, and T. Sasa, "Potential application of ceramic matrix composites to aero-engine components," Composites Part A: Applied Science and Manufacturing, vol. 30, no. 4, pp. 489-496, Apr. 1999.

2. P.L.N. Murthy, S.K. Mital, and R. Shah, "Probabilistic Micromechanics Macromechanics for Ceramic Matrix Composites," NASA Technical Memorandum, 4766, 1997.

3. A.R. Shah, P.L.N. Murthy, S.K. Mital, and R.T. Bhatt, "Probabilistic Modeling of Ceramic Matrix Composite Strength," Journal of Composite Materials, vol. 34, no. 8, pp. 670-688, Apr. 2000.

4. J.A. Dicarlo, H.M. Yun, G.N. Morscher, and R.T. Bhatt, "SiC / SiC Composites for $1200{ }^{\circ} \mathrm{C}$ and Above,"NASA/TM-2004-213048, 2004.

5. F.E. Heredia, M.Y. He, and A.G. Evans, "Mechanical performance of ceramic matrix composite Ibeams," Composites Part A: Applied Science and Manufacturing, vol. 27A, pp. 1157-1167, 1996.

6. Y.W. Kwon and A. Altekin, "Multilevel Micro/Macro-Approach for Analysis of Woven-Fabric Composite Plates," Journal of Composite Materials, vol. 36, no. 8, pp. 1005-1022, 2002.

7. R.K. Goldberg, P.J. Bonacuse, and S.K. Mital, "Investigation of Effect of Material Architecture on the Elastic Response of a Woven Ceramic Matrix Composite,” NASA/TM-2012-217269, 2012. 
8. G.N. Morscher, "Modeling the elastic modulus of 2D woven CVI SiC composites," Composites Science and Technology, vol. 66, no. 15, pp. 2804-2814, Dec. 2006.

9. J. Whitcomb and X. Tang, "Effective Moduli of Woven Composites," Journal of Composite Materials, vol. 35, no. 23, pp. 2127-2144, Dec. 2001.

10. B. Smarslok, R. Haftka, and P. Ifju, "A Correlation Model for Graphite/Epoxy Properties for Propgating Uncertainty in Strain Response," in 23rd Technical Conference of the American Society for Composites, 2008.

11. H. Huang and R. Talreja, "Effects of void geometry on elastic properties of unidirectional fiber reinforced composites," Composites Science and Technology, vol. 65, no. 13, pp. 1964-1981, Oct. 2005.

12. M.B. Goldsmith, B.V. Sankar, R.T. Haftka, and R.K. Goldberg, "Effects of microstructural variability on the mechanical properties of ceramic matrix composites," in American Society for Composites 26th Technical Conference, 2011.

13. N.N. Nemeth, S.K. Mital, and J. Lang, "Evaluation of Solid Modeling Software for Finite Element Analysis of Woven Ceramic Matrix Composites,” NASA/TM-2009-215806, 2009.

14. S.K. Mital, B.A. Bednarcyk, S.M. Arnold, and J. Lang, "Modeling of Melt-Infiltrated SiC/SiC Composite Properties," NASA/TM-2009-215806, 2009.

15. P.J. Bonacuse, S. Mital, and R. Goldberg, "Characterization of the As Manufactured Variability in a CVI SiC/SiC Woven Composite," in Proceedings of ASME Turbo Expo 2011, 2011.

16. A. Reid, "Modeling Microstructures with OOF2," International Journal of Materials and Product Technology, vol. 35, pp. 361-373, 2009.

17. “ABAQUS version 6.9." http://www.simulia.com/products/abaqus_fea.html.

18. H. Zhu, B.B. Sankar, and R.V. Marrey, "Evaluation of Failure Criteria for Fiber Composites Using Finite Element Micromechanics," Journal of Composite Materials, vol. 32, no. 8, 1998.

19. K. Woo and J.D. Whitcomb, "Effects of fiber tow misalignment on the engineering properties of plain weave textile composites," Composite Structures, vol. 31, no. 314, pp. 343-355, 1997.

20. J.D. Whitcomb, C.D. Chapman, and X. Tang, "Derivation of Boundary Conditions for Micromechanics Analyses of Plain and Satin Weave Composites," Journal of Composite Materials, vol. 34, no. 9, pp. 724-747, May 2000. 



\section{Appendix-Geometry and Statistics of Fiber Tows}

\begin{tabular}{|c|c|c|c|}
\hline $\begin{array}{l}\mathrm{X} \text { center, } \\
\mathrm{mm}\end{array}$ & $\begin{array}{l}\text { Y center, } \\
\mathrm{mm}\end{array}$ & $\begin{array}{l}\text { Ellipse major axis, } \\
\mathrm{mm}\end{array}$ & $\begin{array}{l}\text { Ellipse minor axis, } \\
\mathrm{mm}\end{array}$ \\
\hline \multicolumn{4}{|c|}{ Tow statistics cross section 1} \\
\hline 11.8259 & 0.3227 & 1.2724 & 0.1272 \\
\hline 1.707 & 0.302 & 1.2446 & 0.1169 \\
\hline 5.5081 & 0.3012 & 1.2829 & 0.1034 \\
\hline 4.2141 & 0.3105 & 1.2603 & 0.1079 \\
\hline 8.0973 & 0.301 & 1.1998 & 0.1033 \\
\hline 10.5662 & 0.3139 & 1.2412 & 0.1185 \\
\hline 6.7896 & 0.3908 & 1.1239 & 0.1246 \\
\hline 2.8708 & 0.3899 & 1.0129 & 0.1078 \\
\hline 9.2813 & 0.4199 & 1.2101 & 0.0979 \\
\hline 5.4288 & 0.5473 & 1.1864 & 0.1017 \\
\hline 11.7647 & 0.5862 & 1.0505 & 0.0983 \\
\hline 9.273 & 0.6264 & 1.0987 & 0.1324 \\
\hline 1.5695 & 0.6328 & 1.0556 & 0.1303 \\
\hline 2.9538 & 0.6487 & 1.1451 & 0.114 \\
\hline 7.9963 & 0.6573 & 1.1814 & 0.1174 \\
\hline 6.7258 & 0.6995 & 1.0538 & 0.1303 \\
\hline 4.2124 & 0.7307 & 1.0892 & 0.1328 \\
\hline 5.9281 & 0.7468 & 0.9978 & 0.1496 \\
\hline 10.4952 & 0.7435 & 1.1158 & 0.1192 \\
\hline 12.2123 & 0.7657 & 1.0242 & 0.1363 \\
\hline 2.1274 & 0.7828 & 1.0213 & 0.1319 \\
\hline 8.4611 & 0.7805 & 1.2192 & 0.106 \\
\hline 3.393 & 0.8182 & 0.9893 & 0.1319 \\
\hline 9.6977 & 0.8328 & 1.0813 & 0.13 \\
\hline 10.9007 & 0.8569 & 1.1876 & 0.0983 \\
\hline 4.6447 & 0.8688 & 1.1274 & 0.0987 \\
\hline 0.8831 & 0.8866 & 1.0018 & 0.1208 \\
\hline 7.1886 & 0.8975 & 1.1832 & 0.1039 \\
\hline 1.6526 & 1.0518 & 1.1426 & 0.1058 \\
\hline 7.9405 & 1.0565 & 1.1337 & 0.1096 \\
\hline 11.7268 & 1.0719 & 1.1314 & 0.1093 \\
\hline 5.36 & 1.1069 & 1.0721 & 0.1114 \\
\hline 4.1495 & 1.1589 & 1.0777 & 0.1323 \\
\hline 10.5349 & 1.1694 & 1.0593 & 0.1109 \\
\hline 9.2926 & 1.1932 & 1.0401 & 0.1409 \\
\hline 2.894 & 1.2117 & 1.1113 & 0.126 \\
\hline 6.734 & 1.2279 & 1.0715 & 0.1428 \\
\hline
\end{tabular}




\begin{tabular}{|c|c|c|c|}
\hline $\begin{array}{l}\mathrm{X} \text { center, } \\
\mathrm{mm}\end{array}$ & $\begin{array}{l}\text { Y center, } \\
\mathrm{mm}\end{array}$ & $\begin{array}{c}\text { Ellipse major axis, } \\
\mathrm{mm}\end{array}$ & $\begin{array}{l}\text { Ellipse minor axis, } \\
\mathrm{mm}\end{array}$ \\
\hline 1.4715 & 1.2397 & 1.201 & 0.1043 \\
\hline 7.8082 & 1.2495 & 1.1521 & 0.1234 \\
\hline 10.3105 & 1.2746 & 1.1637 & 0.1195 \\
\hline 5.2148 & 1.2874 & 1.0489 & 0.1331 \\
\hline 3.8743 & 1.3058 & 1.1863 & 0.1276 \\
\hline 11.6219 & 1.2997 & 1.1024 & 0.1149 \\
\hline 2.6631 & 1.3823 & 1.143 & 0.1069 \\
\hline 6.4875 & 1.3805 & 1.2191 & 0.0979 \\
\hline 9.0767 & 1.4048 & 1.1021 & 0.113 \\
\hline 8.2122 & 1.5661 & 1.0648 & 0.1226 \\
\hline 4.3273 & 1.5685 & 1.2038 & 0.0928 \\
\hline 10.8071 & 1.595 & 1.2012 & 0.0999 \\
\hline 1.8417 & 1.6103 & 1.1152 & 0.1316 \\
\hline 6.915 & 1.6617 & 1.1768 & 0.1193 \\
\hline 12.0665 & 1.6784 & 1.0758 & 0.1411 \\
\hline 5.678 & 1.7118 & 1.0546 & 0.1279 \\
\hline 3.0996 & 1.7202 & 1.0683 & 0.1247 \\
\hline 9.4525 & 1.7229 & 1.2495 & 0.1232 \\
\hline 0.8017 & 1.7723 & 1.1075 & 0.1377 \\
\hline 4.6011 & 1.7539 & 1.213 & 0.1143 \\
\hline 10.9774 & 1.7563 & 1.2126 & 0.1063 \\
\hline 2.0592 & 1.7788 & 1.1777 & 0.1266 \\
\hline 7.2011 & 1.78 & 1.1483 & 0.1143 \\
\hline 8.4149 & 1.8098 & 1.0323 & 0.1247 \\
\hline 9.6585 & 1.82 & 1.1367 & 0.1055 \\
\hline 3.3848 & 1.855 & 0.9812 & 0.1182 \\
\hline 5.9103 & 1.9109 & 1.1502 & 0.1061 \\
\hline 12.1905 & 1.9169 & 1.1501 & 0.1054 \\
\hline 5.7456 & 2.0386 & 1.1151 & 0.1074 \\
\hline 12.0948 & 2.0588 & 1.1453 & 0.099 \\
\hline 1.892 & 2.1031 & 1.227 & 0.1202 \\
\hline 9.5047 & 2.0991 & 1.1501 & 0.1051 \\
\hline 3.1723 & 2.1341 & 1.2125 & 0.1071 \\
\hline 8.332 & 2.1374 & 1.2167 & 0.1067 \\
\hline 10.7982 & 2.1673 & 1.3097 & 0.1107 \\
\hline 4.5194 & 2.1758 & 1.2211 & 0.1006 \\
\hline 7.0596 & 2.1733 & 1.4017 & 0.0956 \\
\hline \multicolumn{4}{|c|}{ Tow statistics cross section 2} \\
\hline 1.6737 & 0.3078 & 1.1931 & 0.1309 \\
\hline
\end{tabular}




\begin{tabular}{|c|c|c|c|}
\hline $\begin{array}{l}\mathrm{X} \text { center, } \\
\mathrm{mm}\end{array}$ & $\begin{array}{l}\text { Y center, } \\
\mathrm{mm}\end{array}$ & $\begin{array}{l}\text { Ellipse major axis, } \\
\mathrm{mm}\end{array}$ & $\begin{array}{l}\text { Ellipse minor axis, } \\
\mathrm{mm}\end{array}$ \\
\hline 2.8563 & 0.3002 & 1.0428 & 0.1144 \\
\hline 5.5109 & 0.2891 & 1.3167 & 0.0884 \\
\hline 8.1269 & 0.3147 & 1.1837 & 0.1122 \\
\hline 11.7691 & 0.3091 & 1.3295 & 0.1063 \\
\hline 9.2491 & 0.3383 & 1.2579 & 0.1156 \\
\hline 10.5002 & 0.3956 & 1.1974 & 0.1134 \\
\hline 4.1735 & 0.4021 & 1.1877 & 0.1011 \\
\hline 6.7762 & 0.4092 & 1.1549 & 0.1151 \\
\hline 1.5813 & 0.5732 & 1.0971 & 0.1149 \\
\hline 8.0249 & 0.5927 & 1.1807 & 0.1013 \\
\hline 11.7643 & 0.6195 & 1.093 & 0.0974 \\
\hline 5.4169 & 0.6385 & 1.1514 & 0.1168 \\
\hline 4.2555 & 0.6544 & 1.1166 & 0.1239 \\
\hline 6.6895 & 0.7159 & 1.1798 & 0.1195 \\
\hline 2.9604 & 0.7129 & 1.1418 & 0.1156 \\
\hline 10.4979 & 0.7087 & 1.1687 & 0.1103 \\
\hline 9.3024 & 0.7248 & 1.1165 & 0.1182 \\
\hline 5.9884 & 0.771 & 1.0214 & 0.1526 \\
\hline 3.4549 & 0.7851 & 1.0345 & 0.1254 \\
\hline 0.9619 & 0.7724 & 1.0524 & 0.1133 \\
\hline 9.7664 & 0.7982 & 1.0598 & 0.1227 \\
\hline 7.2358 & 0.8146 & 1.1894 & 0.1117 \\
\hline 8.4669 & 0.851 & 1.1468 & 0.1091 \\
\hline 2.1509 & 0.861 & 1.0697 & 0.1183 \\
\hline 4.7019 & 0.9113 & 1.1191 & 0.0984 \\
\hline 10.9374 & 0.9342 & 1.1874 & 0.0903 \\
\hline 4.1439 & 1.0525 & 1.2406 & 0.1077 \\
\hline 7.9346 & 1.0863 & 1.1144 & 0.1179 \\
\hline 10.5119 & 1.0842 & 1.0167 & 0.1056 \\
\hline 1.6763 & 1.1041 & 1.1525 & 0.1226 \\
\hline 11.7475 & 1.1656 & 1.1576 & 0.1179 \\
\hline 6.7428 & 1.1744 & 1.0914 & 0.1377 \\
\hline 5.4176 & 1.1728 & 1.0934 & 0.1077 \\
\hline 2.9005 & 1.1907 & 1.0735 & 0.1031 \\
\hline 9.3138 & 1.2192 & 1.076 & 0.1408 \\
\hline 5.2177 & 1.2699 & 1.0742 & 0.1263 \\
\hline 2.6152 & 1.2749 & 1.1569 & 0.1137 \\
\hline 7.7985 & 1.2825 & 1.1331 & 0.1353 \\
\hline 11.5737 & 1.2759 & 1.1456 & 0.1205 \\
\hline
\end{tabular}




\begin{tabular}{|c|c|c|c|}
\hline $\begin{array}{l}\mathrm{X} \text { center, } \\
\mathrm{mm}\end{array}$ & $\begin{array}{l}\text { Y center, } \\
\mathrm{mm}\end{array}$ & $\begin{array}{l}\text { Ellipse major axis, } \\
\mathrm{mm}\end{array}$ & $\begin{array}{l}\text { Ellipse minor axis, } \\
\mathrm{mm}\end{array}$ \\
\hline 1.46 & 1.2749 & 1.2235 & 0.1107 \\
\hline 9.0871 & 1.3282 & 1.0743 & 0.1203 \\
\hline 10.2911 & 1.3504 & 1.1425 & 0.1281 \\
\hline 3.8687 & 1.373 & 1.2099 & 0.114 \\
\hline 6.5027 & 1.4024 & 1.1788 & 0.0935 \\
\hline 6.883 & 1.5846 & 1.1696 & 0.1152 \\
\hline 10.7584 & 1.5835 & 1.1986 & 0.0976 \\
\hline 4.2744 & 1.6093 & 1.1181 & 0.1209 \\
\hline 3.0782 & 1.6295 & 0.997 & 0.1113 \\
\hline 1.8117 & 1.6511 & 1.1907 & 0.1146 \\
\hline 8.1621 & 1.6665 & 1.0585 & 0.1232 \\
\hline 9.4087 & 1.6881 & 1.154 & 0.1169 \\
\hline 2.0814 & 1.7385 & 1.1985 & 0.1248 \\
\hline 5.6588 & 1.7127 & 1.0362 & 0.1058 \\
\hline 12.0365 & 1.7327 & 1.0748 & 0.143 \\
\hline 8.4016 & 1.7665 & 1.0517 & 0.1243 \\
\hline 4.6415 & 1.7532 & 1.1721 & 0.114 \\
\hline 11.012 & 1.756 & 1.17 & 0.1108 \\
\hline 5.8253 & 1.8146 & 1.2915 & 0.1145 \\
\hline 7.1626 & 1.8511 & 1.1049 & 0.1405 \\
\hline 0.8041 & 1.8574 & 1.1056 & 0.1226 \\
\hline 12.1823 & 1.8667 & 1.1579 & 0.1168 \\
\hline 3.3912 & 1.8836 & 0.9892 & 0.1158 \\
\hline 9.6518 & 1.902 & 1.1254 & 0.101 \\
\hline 1.8619 & 2.0303 & 1.1873 & 0.1136 \\
\hline 8.2869 & 2.0554 & 1.189 & 0.1055 \\
\hline 12.0519 & 2.0997 & 1.1335 & 0.111 \\
\hline 4.5172 & 2.1053 & 1.2071 & 0.1147 \\
\hline 5.709 & 2.1082 & 1.1596 & 0.1093 \\
\hline 10.7351 & 2.1522 & 1.1898 & 0.14 \\
\hline 3.1927 & 2.1549 & 1.2469 & 0.1063 \\
\hline 9.5059 & 2.1732 & 1.1993 & 0.107 \\
\hline 6.9661 & 2.179 & 1.365 & 0.0952 \\
\hline \multicolumn{4}{|c|}{ Tow statistics cross section 3} \\
\hline 4.136 & 0.2752 & 1.195 & 0.1056 \\
\hline 6.7315 & 0.2766 & 1.302 & 0.1059 \\
\hline 9.2026 & 0.3046 & 1.2141 & 0.1148 \\
\hline 2.8746 & 0.3154 & 1.0455 & 0.1158 \\
\hline 10.4575 & 0.3316 & 1.2157 & 0.119 \\
\hline
\end{tabular}




\begin{tabular}{|c|c|c|c|}
\hline $\begin{array}{l}\mathrm{X} \text { center, } \\
\mathrm{mm}\end{array}$ & $\begin{array}{l}\text { Y center, } \\
\mathrm{mm}\end{array}$ & $\begin{array}{l}\text { Ellipse major axis, } \\
\mathrm{mm}\end{array}$ & $\begin{array}{l}\text { Ellipse minor axis, } \\
\mathrm{mm}\end{array}$ \\
\hline 1.5912 & 0.3695 & 1.2384 & 0.1224 \\
\hline 11.6915 & 0.389 & 1.2757 & 0.1164 \\
\hline 7.996 & 0.3963 & 1.0791 & 0.1093 \\
\hline 5.4379 & 0.3925 & 1.2207 & 0.0955 \\
\hline 6.7242 & 0.5482 & 1.2331 & 0.1007 \\
\hline 2.9898 & 0.6169 & 1.1655 & 0.111 \\
\hline 10.5125 & 0.6193 & 1.0788 & 0.1174 \\
\hline 4.2271 & 0.6373 & 1.1232 & 0.1289 \\
\hline 9.3138 & 0.6872 & 1.0427 & 0.1362 \\
\hline 5.5016 & 0.6979 & 0.9558 & 0.126 \\
\hline 8.0722 & 0.7081 & 1.1068 & 0.1192 \\
\hline 1.6283 & 0.7161 & 1.0343 & 0.1401 \\
\hline 4.8013 & 0.7458 & 1.0692 & 0.1374 \\
\hline 11.8099 & 0.7105 & 1.1051 & 0.1078 \\
\hline 11.0198 & 0.7659 & 1.0282 & 0.1243 \\
\hline 7.3291 & 0.7757 & 1.1562 & 0.1171 \\
\hline 2.2665 & 0.7903 & 1.0912 & 0.1304 \\
\hline 1.0165 & 0.7949 & 1.083 & 0.1278 \\
\hline 8.5875 & 0.8162 & 1.1039 & 0.1179 \\
\hline 9.8653 & 0.8518 & 1.1084 & 0.1153 \\
\hline 3.5119 & 0.8743 & 1.1389 & 0.1053 \\
\hline 6.0986 & 0.8921 & 1.1215 & 0.1287 \\
\hline 2.8925 & 1.0433 & 1.1392 & 0.0904 \\
\hline 9.2832 & 1.0743 & 1.1295 & 0.1085 \\
\hline 6.7235 & 1.0918 & 1.1845 & 0.1196 \\
\hline 5.4075 & 1.1553 & 0.9551 & 0.1335 \\
\hline 10.4865 & 1.1619 & 0.9952 & 0.1332 \\
\hline 11.7382 & 1.1657 & 1.194 & 0.1301 \\
\hline 4.1748 & 1.1708 & 1.1401 & 0.1277 \\
\hline 1.6704 & 1.1936 & 1.0817 & 0.1371 \\
\hline 7.9635 & 1.2056 & 1.1713 & 0.1201 \\
\hline 6.4832 & 1.2361 & 1.1941 & 0.108 \\
\hline 9.0871 & 1.2556 & 1.107 & 0.1259 \\
\hline 2.6413 & 1.2668 & 1.1536 & 0.1305 \\
\hline 3.8634 & 1.2798 & 1.2106 & 0.1301 \\
\hline 10.2675 & 1.3096 & 1.1818 & 0.1176 \\
\hline 11.5756 & 1.334 & 1.0945 & 0.1131 \\
\hline 1.4281 & 1.3465 & 1.2318 & 0.0991 \\
\hline
\end{tabular}




\begin{tabular}{|c|c|c|c|}
\hline $\begin{array}{c}\mathrm{X} \text { center, } \\
\mathrm{mm}\end{array}$ & $\begin{array}{l}\text { Y center, } \\
\mathrm{mm}\end{array}$ & $\begin{array}{c}\text { Ellipse major axis, } \\
\mathrm{mm}\end{array}$ & $\begin{array}{l}\text { Ellipse minor axis, } \\
\mathrm{mm}\end{array}$ \\
\hline 5.2365 & 1.3835 & 1.1181 & 0.1113 \\
\hline 7.748 & 1.3879 & 1.1634 & 0.1101 \\
\hline 5.5429 & 1.5665 & 1.0873 & 0.1079 \\
\hline 9.357 & 1.584 & 1.2127 & 0.1067 \\
\hline 11.9784 & 1.5946 & 1.1746 & 0.1069 \\
\hline 2.9439 & 1.6029 & 0.9763 & 0.117 \\
\hline 1.7139 & 1.6274 & 1.1136 & 0.1358 \\
\hline 6.786 & 1.7018 & 1.2993 & 0.1267 \\
\hline 8.0514 & 1.6877 & 1.0943 & 0.1237 \\
\hline 4.2128 & 1.7177 & 1.1098 & 0.1226 \\
\hline 10.7531 & 1.7091 & 1.1275 & 0.1028 \\
\hline 3.3673 & 1.7402 & 1.0276 & 0.1365 \\
\hline 9.6981 & 1.7489 & 1.2375 & 0.1221 \\
\hline 12.1786 & 1.735 & 1.0747 & 0.1315 \\
\hline 0.7638 & 1.7668 & 1.0966 & 0.1272 \\
\hline 5.8485 & 1.7775 & 1.0101 & 0.1321 \\
\hline 7.1819 & 1.8233 & 1.1472 & 0.1211 \\
\hline 8.3963 & 1.8478 & 1.0745 & 0.1119 \\
\hline 2.046 & 1.8645 & 1.2086 & 0.1162 \\
\hline 4.6151 & 1.9099 & 1.1971 & 0.0997 \\
\hline 10.968 & 1.9004 & 1.1704 & 0.0925 \\
\hline 10.727 & 2.0825 & 1.2386 & 0.1254 \\
\hline 6.96 & 2.0731 & 1.233 & 0.095 \\
\hline 3.1143 & 2.1121 & 1.2476 & 0.1109 \\
\hline 9.4332 & 2.1263 & 1.1823 & 0.1091 \\
\hline 4.4191 & 2.1504 & 1.1889 & 0.1173 \\
\hline 8.2915 & 2.167 & 1.3278 & 0.0992 \\
\hline 1.8788 & 2.1693 & 1.2828 & 0.1106 \\
\hline 12.0206 & 2.1736 & 1.213 & 0.0994 \\
\hline 5.6526 & 2.1987 & 1.1947 & 0.1094 \\
\hline
\end{tabular}





\begin{tabular}{|c|c|c|c|c|c|}
\hline \multicolumn{5}{|c|}{ REPORT DOCUMENTATION PAGE } & $\begin{array}{l}\text { Form Approved } \\
\text { OMB No. 0704-0188 }\end{array}$ \\
\hline \multicolumn{6}{|c|}{$\begin{array}{l}\text { The public reporting burden for this collection of information is estimated to average } 1 \text { hour per response, including the time for reviewing instructions, searching existing data sources, gathering and maintaining the } \\
\text { data needed, and completing and reviewing the collection of information. Send comments regarding this burden estimate or any other aspect of this collection of information, including suggestions for reducing this } \\
\text { burden, to Department of Defense, Washington Headquarters Services, Directorate for Information Operations and Reports (0704-0188, } 1215 \text { Jefferson Davis Highway, Suite } 1204 \text {, Arlington, VA } 22202-4302 \text {. } \\
\text { Respondents should be aware that notwithstanding any other provision of law, no person shall be subject to any penalty for failing to comply with a collection of information if it does not display a currently valid OME } \\
\text { control number. } \\
\text { PLEASE DO NOT RETURN YOUR FORM TO THE ABOVE ADDRESS. }\end{array}$} \\
\hline \multicolumn{2}{|c|}{$\begin{array}{l}\text { 1. REPORT DATE (DD-MM-YYYY) } \\
01-01-2013\end{array}$} & \multicolumn{3}{|c|}{$\begin{array}{l}\text { 2. REPORT TYPE } \\
\text { Technical Memorandum }\end{array}$} & 3. DATES COVERED (From - To) \\
\hline \multirow{3}{*}{\multicolumn{5}{|c|}{$\begin{array}{l}\text { 4. TITLE AND SUBTITLE } \\
\text { Effects of Microstructural Variability on Thermo-Mechanical Properties of a Woven Ceram } \\
\text { Matrix Composite }\end{array}$}} & 5a. CONTRACT NUMBER \\
\hline & & & & & 5b. GRANT NUMBER \\
\hline & & & & & 5c. PROGRAM ELEMENT NUMBER \\
\hline \multirow{3}{*}{\multicolumn{5}{|c|}{$\begin{array}{l}\text { 6. AUTHOR(S) } \\
\text { Goldsmith, Marlana, B.; Sankar, Bhavani, V.; Haftka, Raphael, T.; Goldberg, Robert, K. }\end{array}$}} & 5d. PROJECT NUMBER \\
\hline & & & & & 5e. TASK NUMBER \\
\hline & & & & & $\begin{array}{l}\text { 5f. WORK UNIT NUMBER } \\
\text { WBS 984754.02.07.03.16.03.02 }\end{array}$ \\
\hline \multicolumn{5}{|c|}{$\begin{array}{l}\text { 7. PERFORMING ORGANIZATION NAME(S) AND ADDRESS(ES) } \\
\text { National Aeronautics and Space Administration } \\
\text { John H. Glenn Research Center at Lewis Field } \\
\text { Cleveland, Ohio 44135-3191 }\end{array}$} & $\begin{array}{l}\text { 8. PERFORMING ORGANIZATION } \\
\text { REPORT NUMBER } \\
\text { E-18560 }\end{array}$ \\
\hline \multirow{2}{*}{\multicolumn{5}{|c|}{$\begin{array}{l}\text { 9. SPONSORING/MONITORING AGENCY NAME(S) AND ADDRESS(ES) } \\
\text { National Aeronautics and Space Administration } \\
\text { Washington, DC 20546-0001 }\end{array}$}} & $\begin{array}{l}\text { 10. SPONSORING/MONITOR'S } \\
\text { ACRONYM(S) } \\
\text { NASA }\end{array}$ \\
\hline & & & & & $\begin{array}{l}\text { 11. SPONSORING/MONITORING } \\
\text { REPORT NUMBER } \\
\text { NASA/TM-2013-217817 }\end{array}$ \\
\hline \multicolumn{6}{|c|}{$\begin{array}{l}\text { 12. DISTRIBUTION/AVAILABILITY STATEMENT } \\
\text { Unclassified-Unlimited } \\
\text { Subject Categories: } 24 \text { and } 39 \\
\text { Available electronically at http://www.sti.nasa.gov } \\
\text { This publication is available from the NASA Center for AeroSpace Information, 443-757-5802 }\end{array}$} \\
\hline \multicolumn{6}{|c|}{$\begin{array}{l}\text { 13. SUPPLEMENTARY NOTES } \\
\text { Submitted to Elsevier Publishing Composites A Journal. }\end{array}$} \\
\hline \multicolumn{6}{|c|}{$\begin{array}{l}\text { 14. ABSTRACT } \\
\text { The objectives of this paper include identifying important architectural parameters that describe the SiC/SiC five-harness satin weave } \\
\text { composite and characterizing the statistical distributions and correlations of those parameters from photomicrographs of various cross } \\
\text { sections. In addition, realistic artificial cross sections of a 2D representative volume element (RVE) are generated reflecting the variability } \\
\text { found in the photomicrographs, which are used to determine the effects of architectural variability on the thermo-mechanical properties. } \\
\text { Lastly, preliminary information is obtained on the sensitivity of thermo-mechanical properties to architectural variations. Finite element } \\
\text { analysis is used in combination with a response surface and it is shown that the present method is effective in determining the effects of } \\
\text { architectural variability on thermo-mechanical properties. }\end{array}$} \\
\hline \multicolumn{6}{|c|}{$\begin{array}{l}\text { 15. SUBJECT TERMS } \\
\text { Ceramix matrix composites (CMCs); Micromechanics }\end{array}$} \\
\hline \multicolumn{3}{|c|}{ 16. SECURITY CLASSIFICATION OF: } & $\begin{array}{l}\text { 17. LIMITATION OF } \\
\text { ABSTRACT }\end{array}$ & $\begin{array}{l}\text { 18. NUMBER } \\
\text { OF }\end{array}$ & $\begin{array}{l}\text { 19a. NAME OF RESPONSIBLE PERSON } \\
\text { STI Help Desk (email:help@sti.nasa.gov) }\end{array}$ \\
\hline $\begin{array}{l}\text { a. REPORT } \\
\text { U }\end{array}$ & $\begin{array}{l}\text { b. ABSTRACT } \\
\text { U }\end{array}$ & $\begin{array}{l}\text { c. THIS } \\
\text { PAGE } \\
\text { U }\end{array}$ & UU & $\begin{array}{c}\text { PAGES } \\
30\end{array}$ & $\begin{array}{l}\text { 19b. TELEPHONE NUMBER (include area code) } \\
\text { 443-757-5802 }\end{array}$ \\
\hline
\end{tabular}



